\title{
A Scandinavian tragedy
}

D. W. Jones ${ }^{1}$

IN BRIEF

- Dentistry's contribution to environmenta pollution by mercury is negligible compared to other sources.

- Amalgam has many distinct scientific and clinical advantages compared to composite restorative materials.

- Scientific principles and knowledge have been ignored by governments when developing health and environmental legislation regarding the use of dental amalgam.

This paper briefly reviews the logic surrounding the controversial banning of dental amalgam by the Norwegian government. The very small contribution from dentistry to environmental mercury pollution and the significant advantages of amalgam as a dental restorative are emphasised.

In recent years the controversy surrounding the use of dental amalgam has been as much a political issue as a scientific one. The question of environmental pollution by dental waste is clearly a political issue in Norway and other Scandinavian countries. Dentistry is indeed a pawn in the chess game of industrial pollution politics being undertaken by government agencies in Europe and North America.

No one disputes the fact that in the past 20 years or so the amount of mercury entering the environment has increased by a factor of about three in both fresh water and oceans. Acid rain, another product from industrial pollution, also increases the level of mercury eroded from rocks. The lesson from the tragic Minamata disaster of 1956 in Japan was not fully heeded. This was a result of the discharging of industrial waste inorganic mercury into the Minamata bay. ${ }^{1}$ Ironically a potential repeat of the Minamata disaster lies off the coast of Norway; a German U-boat from World War II was sunk with a reported cargo of $65,000 \mathrm{~kg}$ of mercury on board. ${ }^{2,3}$ The Norwegian Environmental Ministry is currently attempting to deal with this.

Professor of Biomaterials, Division of Biomaterials, Faculty of Dentistry, Dalhousie University, 5981 University Avenue, Halifax, Nova Scotia, Canada, B3H 3J5 Correspondence to: Professor Derek W. Jones

Email:dwjones@hfx.eastlink.ca

DOI: 10.1038/bdj.2008.151

British Dental Journal 2008; 204: 233-234
However, recognition of the problem of mercury pollution of the environment has resulted in significant curtailment of the use of mercury by some segments of industry. Sweden, to its credit, banned the use of mercury in the pulp and paper industry and the use of methyl mercurycoated seed 42 years ago in $1966 .{ }^{4}$

The Norwegian Government produced a White Paper on mercury in 2006, which was debated in Parliament and a national strategy was agreed with targets to reduce release of mercury into the environment by 2010 and 2020. The European Union (Norway is presently not a member) is likely to review once again the mercury issue.

With the banning of dental amalgam in Norway as of 1 January $2008^{5}$ and the possibility of similar proposals to ban amalgam in Sweden and Denmark, it is perhaps ironic that some of the most important and valid scientific studies confirming the safety of dental amalgam have been conducted in Sweden. ${ }^{6,7}$

\section{No impact from banning dental mercury}

It is true to say that if the mercury pollution from dentistry were reduced to zero tomorrow, it would not have any impact on the mercury pollution problem worldwide.

From the mid-1980s, sensational, confusing and misleading media reports about health issues related to dental amalgam have constantly bombarded the public. $^{8}$ Minority non-scientific viewpoints have significantly influenced public opinion on this issue. The mobilisation of irrational public fear has been employed by lobby groups to pressure governments to change public policy. ${ }^{4}$ Some members of the dental profession have attempted to take advantage of the public's perception regarding dental amalgam use. This prompted a top international Norwegian dental scientist to write, 'The removal of any restoration, whether it is made of amalgam, composite resin, or any other material, is unethical if it is done on a dentist's diagnosis and treatment of systemic diseases'. ${ }^{9}$

\section{Norway - no reply}

On 7 January 2008 I wrote to the Norwegian Ministry of the Environment expressing my dismay at their decision of 14 December 2007 to ban the use of dental amalgam as of 1 January 2008. To date I have had no reply from the Norwegian Government. I strongly believe that it is important that governments use sound scientific knowledge and scientific principles when developing health and environmental legislation. Dentistry is an applied science and the profession of dentistry needs to bring issues such those dealing with dental amalgam to the attention of governments.

The Norwegian legislation aims to prohibit the production, importation, exportation, sale and use of substances that contain mercury. However, the prohibition does not cover mercury that occurs 
naturally in coal, ore and ore concentrations (presumably cinnabar could be included in this category). It should also be noted that Sweden and Denmark also plan to introduce similar legislation in 2008. Thus this action by Norway sets an important precedent and needs to be challenged.

I have expressed my very strong objection to this bureaucratic travesty to the Norwegian Government for the following reasons:

- At least 50\% of environmental mercury pollution comes from natural sources

- Some $42 \%$ of environmental mercury pollution comes from the burning of fossil fuels (and yet for the moment the Norwegian Government excludes coal)

- No valid scientific studies have ever shown that dental amalgam poses a health hazard to patients, to dentists or the environment

- A patient with 10 amalgam surfaces in their mouth would have a mercury intake into their blood which would be only $2 \%$ of the World Health Organisation's acceptable daily intake (WHO ADI $40 \mu \mathrm{g} /$ day) for mercury, with no adverse health effects

- I have calculated that the environmental impact of mercury from 800,000 dental offices worldwide would represent between 0.04 and $0.2 \%$ of the total worldwide environmental mercury pollution from all sources (this would be significantly reduced by using amalgam traps ${ }^{10}$ which are increasingly being used)

- I have also calculated that the worldwide environmental impact into the sewer of mercury from 20 billion amalgam surfaces in people's mouths represents between 0.01 and $0.07 \%$ of the total environmental mercury pollution.

It would be entirely understandable if Norway banned the burning of fossil fuels together with the unsafe disposal of mercury-containing batteries and lamps. Estimates of mercury put into the sewer system by dentistry are insignificant in comparison to the worldwide release of mercury that has been estimated as between 6.3 million $\mathrm{kg}^{11}$ and 22-33 million kg. ${ }^{12}$ Whatever the actual number is for the total mercury released into the environment on a global scale, the amount released from dental procedures and dental amalgam is not a significant contributor to the problem.

\section{No conclusive scientific evidence}

The banning by Norway of a very sound, effective and valuable dental material makes no clinical, scientific, economic or environmental sense at all. Unlike composite resin-based materials (alternatives to amalgam fillings), amalgam has an elastic modulus (stiffness) similar to natural tooth enamel. For this reason, amalgam can provide support to the tooth structure at the margins. Composite resin fillings, on the other hand, being less stiff than natural tooth enamel, are unable to support the tooth structure at the margins to the same extent. Unlike amalgam, composite resin materials take up water, which is detrimental to their mechanical properties. Amalgam has wear characteristics similar to natural tooth tissue whilst composite materials wear more readily. In addition, interproximal placement of amalgam is much easier than for composite. Composite resin materials retain a greater amount of plaque compared to amalgam, which can predispose to dental caries adjacent to the composite restorations. It is well known that composite resin materials are required to be replaced more frequently than dental amalgam. Furthermore, each time a restoration has to be replaced, additional natural tooth structure is lost. It is indeed a major Scandinavian tragedy if dental amalgam is banned.
At present, there is no conclusive evidence in the scientific literature to demonstrate a link between the cause of irreversible neurological disorders or of impaired kidney function and mercury vapours from dental amalgam. Animal experiments to date have not been able to establish conclusively any cause-andeffect link that can be extrapolated to human exposure to mercury from amalgam restorations. ${ }^{4,13}$

Mercury pollution from dentistry is insignificant compared to that from industrial use and natural sources. The banning of dental amalgam is a political issue that will not impact on total worldwide mercury pollution but will regrettably reduce the dental health benefits provided by the use of dental amalgam. ${ }^{14}$

1. Smith W E, Smith A M. Minamata: a warning to the world. London: Chatto \& Windus, 1975. ISBN 7011-2131-9

2. Cowell A, Gibbs W. German sub menaces north sea 61 years after sinking. International Herald Tribune Europe 2007 January 10.

3. Oziewicz E. Toxic shield guards U-864's secrets. The Globe and Mail (Canada) 2006 December 7.

4. Jones $D$ W. The enigma of amalgam in dentistry. J Can Dent Assoc 1993; 59: 155-166.

5. Norwegian Ministry of the Environment. Amendment of regulations of 1 June 2004 no 922 relating to restrictions on the use of chemicals and other products hazardous to health and the environment (product regulations). Oslo: Norwegian Ministry for the Environment, 2007.

6. Berglund A. Estimation by 24-hour study of the daily dose of intra-oral mercury vapour inhaled after release from dental amalgam. J Dent Res 1990; 69: 1646-1651.

7. Berglund A, Pohl L, Olsson S, Bergman M. Determination of the rate of release of intra-oral mercury vapour from amalgam. J Dent Res 1988; 67: 1235-1242.

8. Jones D W. Giving science a bad name. J Can Dent Assoc 1991; 57: 291-293.

9. Mjør I A. The obituary for amalgam. Quintessence Int 1991; 22: 331-332.

10. International Standards Organisation. ISO 11143:1999: Dental equipment-amalgam separators. Geneva: ISO Central Secretariat, 1999.

11. Chong R. Mercury reduction and product stewardship. Paper presented at Mercury Elimination and Reduction Symposium Pollution Probe, Toronto May 5-6 1997.

12. Chin G, Chong J, Kluczewska A, Lau A, Gorjy S, Tennant M. The environmental effects of dental amalgam. Aust Dent J 2000; 45: 246-249.

13. Jones D W. Exposure and absorption and the crucial question of limits for mercury. J Can Dent Assoc 1999; 65: 788-792.

14. Jones D W. Putting dental mercury pollution into perspective. Br Dent J 2004; 197: 175-177. 